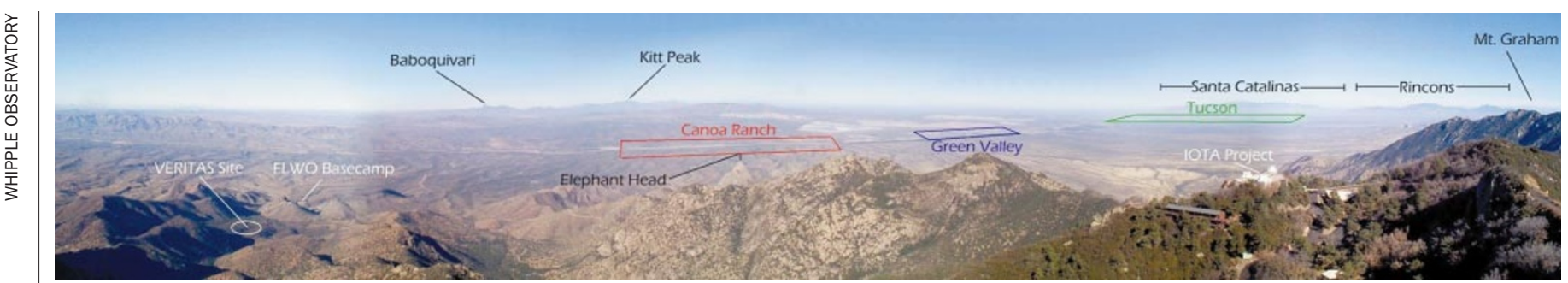

Panoramic view: a $180^{\circ}$ view from the summit of Mount Hopkins shows the Canoa Ranch development site 20 miles south of Tucson.

\title{
US astronomers contest building project
}

[WASHINGTON] A dispute over proposed commercial development at the foot of Mount Hopkins in southern Arizona threatens to end years of peaceful coexistence between astronomers and land developers in the state.

Astronomers have opposed the project, fearing that light pollution will degrade viewing conditions at the Whipple Observatory, the Multiple Mirror Telescope (MMT) and other facilities on the mountain.

Fairfield Homes, a developer based in Green Valley, Arizona, wants to expand plans for low-density housing to include commercial development. It has threatened astronomers with a lawsuit if they continue to speak out against the project. Fairfield's application for commercial development on the 5,200acre Canoa Ranch site 20 miles south of Tucson was scheduled to go before a local board of supervisors at a public hearing this week.

In a letter sent two days before Christmas, Frank Cassidy, an attorney for Fairfield, accused astronomers from the Whipple Observatory and other institutions of lobbying against the project "under the guise of providing scientific information".

Among the "improper actions" cited were the distribution of a brochure on light pollution at an earlier hearing by Whipple public affairs officer Dan Brocious.

Cassidy claimed that, because the Smithsonian Institution observatories are publicly owned, interfering with Fairfield's $\$ 900$ million development could amount to a government "taking" of private property, for which opponents of the project would be liable.

Cassidy's letter threatened the institutions as well as individuals - including Robert Kirshner of the Harvard-Smithsonian Center for Astrophysics and MMT observatory director Craig Foltz — with "appropriate legal action" unless they stopped their "lobbying" against the Canoa Ranch application.

Also named in Cassidy's letter was Chris Luginbuhl, an astronomer at the US Naval Observatory's station in Flagstaff, Arizona, and an expert on the impact of lighting on observatories. Luginbuhl was asked by the Whipple Observatory and the University of Arizona (which co-owns the MMT) to provide a critique of Fairfield's estimate of light pollution from Canoa Ranch if commercial development goes ahead.
His estimates were in some cases six to seven times higher than the developer's, based on different assumptions about the types and amount of commercial lots that would be built, and how much light they would produce. In a worst case scenario, says Luginbuhl, commercial development could result in a 10 to 15 per cent brightening of the sky at Mount Hopkins.

Frank Thomson, a planning consultant to Fairfield, says his client is sensitive to astronomers' worries, and is committed to producing no more light pollution than would result from the already approved plan for 1,200 homes.

But Luginbuhl and other astronomers say verbal promises count for little. The plans could change, or Fairfield could sell the property after permission is granted for development to someone with different ideas.

Thomson says astronomers have been unwilling to meet Fairfield representatives to work out strategies for mitigating light pollution. Normally, light pollution can be reduced through measures such as light shielding, or by local ordinances that restrict lighting after certain hours. But astronomers say that may not be possible in this case, given the type and scale of the proposed development. "The developer believes we can hand them a set of lighting ordinances that can make it OK," says Brocious. "If we had a solution, we would have forwarded it."

Luginbuhl agrees that even municipal codes like those in place for Flagstaff, which he says are among the strictest in the world in protecting astronomers' interests, could not preserve viewing conditions on Mount Hopkins if commercial development occurs to the limit allowed by the proposed plan.

The issue will undoubtedly come up later this year when a committee representing both astronomers and developers, cochaired by Don Davis of the Tucson-based Planetary Science Institute, takes up the matter of revised lighting codes for the Tucson area, which also includes Kitt Peak National Observatory. The codes have been revised several times since being established in 1972.

Thomson says it is "unfortunate" that tensions have escalated over Canoa Ranch after more than 10 years of astronomers and developers working out their differences in a friendlier way. But astronomers were rankled by what Smithsonian attorney James Wilson calls Cassidy's "inappropriate attempt to intimidate," and what a Tucson newspaper termed "Fairfield's crude threat".

Cassidy's letter advised astronomers to "take your heads out of the sand and recognize the reality that development will inevitably occur in the vicinity of Mount Hopkins".

Wilson says Canoa Ranch is "a big issue for us," and that astronomers on Mount Hopkins have every right to weigh in with their opinions as "affected landowners". As of last weekend, some 1,500 astronomers worldwide had signed a petition opposing "attempts to silence [astronomers] through intimidation". Faced with such criticism, Cassidy was more moderate in a 7 January reply to Wilson, saying "Fairfield has no desire to litigate against the observatory".

Another reason for the acrimony over Canoa Ranch is the high political and financial stakes in the project. Fairfield faced political opposition before this week's hearing, with two of five county supervisors on record as opposing the development application even before the light pollution issue surfaced.

Luginbuhl believes an underlying reason for the heightened conflict is that developers are beginning to encroach on what were until recently considered remote, dark-sky locations. "Astronomers are beginning to wake up to the realization that we can't run any further," he says.

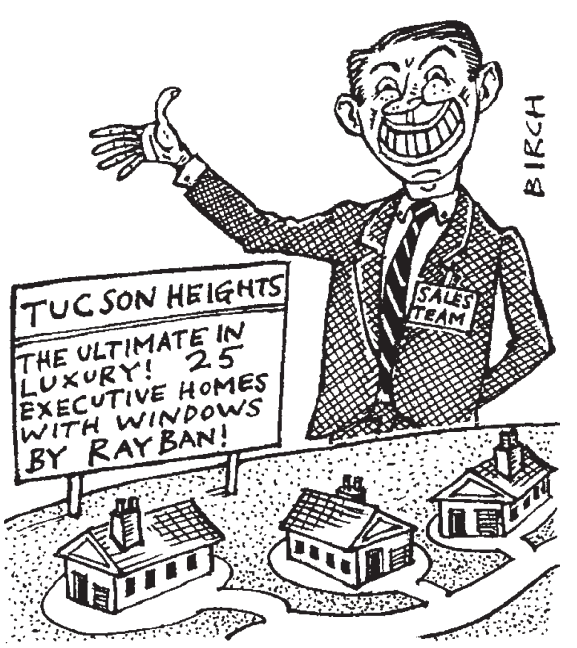

